\title{
Use of Rogowski Coil as Current Transducer for Distance Relay Reach Correction
}

\author{
Avinash Namdeo Sarwade ${ }^{1}$, Pradeep K. Katti ${ }^{2}$, and Jayant G. K. Ghodekar ${ }^{3}$ \\ ${ }^{1.2}$ Department of Electrical Engineering, Dr. BATU, Lonere, Raigarh, India \\ ${ }^{3}$ Retd. Principal, GCOE, Karad, India \\ asarwade@yahoo.com,pk_katti2003@yahoo.com,jgghodekar@gmail.com
}

\begin{abstract}
Conventional iron core CT gets saturated with increase in system X/R ratio, burden connected across it under normal condition and presence of DC component in symmetrical current waveform under faulty condition. CT saturation causes distance relay (DR) to under reach and operate it with certain time delay. The problem becomes more critical when fault takes place near to the boundary of first zone of DR. RC has become more popular for measurement of normal and complex transient current due to its inherent linearity, wide operating current range, reduced size, cost and its flexibility in operation. With the development of today's microprocessor/numerical relay, Rogowski coil (RC) has become more suitable for protective relaying applications. This paper presents use of RC for measurement of current in distance protection scheme (DPS). Case study for validation of use of RC is carried out on Electric furnace system. The simulation results of DPS used for protection of part of 220kV IEEE 9 Bus system shows excellent performance of RC over conventional CT during normal and abnormal conditions.
\end{abstract}

Keywords: Distance Relay; Under-reach; Rogowski coil; Current Transformer Saturation; PSCAD/EMTDC.

\section{Introduction}

Distance relays (DRs) are used for protection of high voltage transmission line as they provide more secure, faster and reliable protection [1]. Fault rate is usually much higher in transmission lines as compared to other components of the power system. The occurrence of the different types of the faults produces very large currents in the power system [2]. Conventional Current Transformer (CT) utilize an iron core and winding ratio to step down these currents to a more manageable level for the secondary devices such as protective relays and meters[3]. Adequate CT's are essential because of security and selectivity in distance protection application. CT experience errors in magnitude and phase angles. The most serious errors are those attributable to severe saturation of the CT core. CT saturation, in general cause distance relay to see lower effective current than they would see and causes them to reach a shorter distance than they would, if there were no CT saturation. This also causes the distance protection scheme to provide its trip decision with certain time delay [4].

CT performance characteristics are specified by American National Standard Institute (ANSI)/Institute of Electrical and Electronics Engineers (IEEE) Standard [5]. This standard contains some steps to avoid CT saturation. Many of these steps result in large size CTs which is unacceptable from commercial and economical point of view [6]. Now days the trend in the switchgear industry is to work on reduction of current and voltage transducers size and their delivery times at consumer premises. To specify CTs, the manufacturers also need detailed information regarding electrical system, where the transducers are going to be used. The process of collection of detailed and correct information for CT design requires more effort and is time consuming [7]. These CTs need to be replaced with high rating CTs in case of future expansion of an electrical system. Therefore it is necessary to select transducer which operates with wide current range without saturation.

Received: July $11^{\text {st }}, 2016$. Accepted: December $7^{\text {th }}, 2016$

DOI: 10.15676/ijeei.2016.8.4.8 
The behavior of distance relay with CT saturation is analyzed with an algorithm proposed in [8]. The algorithm calculates phasors of the current with variable data window for unsaturated CT. The amplitude and phase angle errors are approximately $10 \%$ and $4^{0}$. This method is not consistent when CT secondary carries highly inductive element in its burden. In [9], proposed method helps to reconstruct CT secondary current based on mathematically adding magnetizing current to the measured CT secondary current. This method is practicable, if the winding impedance, CT secondary burden, magnetization characteristics and remanent flux are accurately available.

CT nonlinear model is identified by means of a separable least squares method [10]. In this method primary current is estimated from distorted secondary current. This method is a good solution for offline waveform reconstruction but not suitable for applications associated with online protection and control equipments used in power system where a decision has to be taken as fast as possible. In [11], a methodology capable of converting a sampled current waveform that is distorted by CT saturation to a compensated current waveform is proposed. To control the operation of certain protection functions, various saturation detection techniques are used. The main disadvantage of this approach is the time delayed operation and low/poor sensitivity.

Proposed algorithm helps to calculate core flux from the secondary current, to compensate CT saturation effect. This algorithm helps to detect saturation level of CT based on its given parameters [12]. The function to be developed based on given CT parameters represent approximately the non linear characteristics of CT model. In [13], Performance of distance relay protection with conventional CT and nonconventional fibre optic current sensor (FOCS) is investigated. FOCS helps to provide better security in distance protection application under CT saturation condition. The errors may get introduced in the result due to the magnetic fields induced by the currents through other conductors.

An approach uses unsaturated current section and a saturation detection technique for accurate identification of the unsaturated sections of the measured current waveform [14]. Furthermore, it may not faithfully recognize the saturation starting and end time instants, particularly under inductive burden conditions. In addition, a short-length moving data-window used to find the phasor value based on the unsaturated current portion is inherently susceptible to noise and harmonics. In [15], Elman neural network based compensation scheme for distorted secondary current is proposed. The impedance trajectories and trip decision with quadrilateral trip boundary due to distorted secondary and compensated secondary current are compared. This method can't be universally adopted for different CTs, because CT saturation effect varies from CT to CT, even for CTs of same design.

DR algorithm based on a time-domain phase comparator with a smaller burden is proposed [16]. The algorithm incorporates a filter which helps to remove decaying DC component in the current. The filter used in the method adds some time delay in the execution time of the algorithm. This method only suits for digital and numerical relay, not for conventional electromechanical relay. In [17], an idea is introduced using least error squares method and a simple offline lookup table, to filter out the decaying dc component and CT saturation effects. The proposed algorithm gives the fundamental sinusoidal component of current correctly. This method can respond using only five current samples. To provide more immunity against noise and harmonics the window size could also be increased. Calculations involve in this method increases complexity.

An approach based on Gaussian Mixture Models (GMMs) is presented to detect CT saturation. GMMs are trained with CT secondary current at different fault currents [18]. GMM has computation issue, fail to work with the problem of high dimensions. The user has to set the number of mixture models that the algorithm will try and fit to the training dataset. In [19], the factors which consider sizing of CTs for line protection applications are discussed. To improve the security and speed of protection scheme, the advances in protection element design under CT saturation conditions are presented. The method suggests increasing core size of the CT, which is not feasible solution. 
Hilbert Transform (HT) and Discrete Fourier Transform (DFT) based combined approach is proposed for estimation of fundamental phasor for removing decaying DC components [20]. This approach includes limited frequency switching speed and general complexity. In [21], Digital signal controllers (DSCs) are developed for real time studies of the dynamic behavior of the air-gapped CT's used in power system protection and measurement systems. A technique is presented to overcome the CT secondary current distortion in case of gapped core where residual flux is insignificant. The air gap CT produces less correctness for relaying application and replacement of saturable CT with air gapped core CT is highly expensive.

Different techniques and algorithms have been proposed by different authors to overcome CT saturation and its effect on DR performance [8]-[21]. The following drawbacks are observed in their methodologies or algorithms as they

- Limits the use for either offline operation or online operation only[10, 16]

- Consider approximate nonlinear CT model [13]

- Consider approximate values of some parameters like residual flux, winding impedance, inductive burden etc [9]

- Suggest to increase size of CT to accommodate DC offset, which will make it bulky and expensive [19]

- Suffer from magnetic fields produced by adjacent conductor [13]

- Suffer from harmonics and noise [14]

- Suffer from time delay and sensitivity [11]

So to overcome the above issues altogether, it is suggested to choose an alternative to CT. Rogowski Coil (RC) has attracted much attention of electric power industry as it can meet the requirements of protective relaying due to its superior performance, inherent linearity, outstanding dynamic response, wide bandwidth and no magnetic saturation [22-23]. So far RC is used as current transducer in differential and over current protection. This paper presents use of RC as a best alternative to conventional CT in $220 \mathrm{kV}$ distance protection scheme. The paper is structured as follows: in section 'theory of operation', concepts of distance protection scheme, CT and RC are reviewed; in section 'modelling', conventional CT, ideal CT RC, IEEE 9 bus and distance protection scheme is modelled by using PSCAD; in section 'Case study and Simulation Results', implementation of RC in low voltage system and the series of simulation results of transient response, magnetization characteristics, apparent impedance trajectories and time of operation in distance protection scheme are discussed and compared.

\section{Theory of operation}

\section{A. Distance Protection Scheme}

The distance protection scheme used for protection of a high voltage transmission line $\mathrm{AB}$ with impedance $Z_{\text {Line }}$ is shown in Figure.1 [24]. The voltage and current signals are collected with the help of voltage transformer (VT) and CT from line AB during normal and abnormal conditions. The transformed signals (VT and CT secondary signals) are used to calculate the impedance on secondary side known as apparent impedance, Zap.

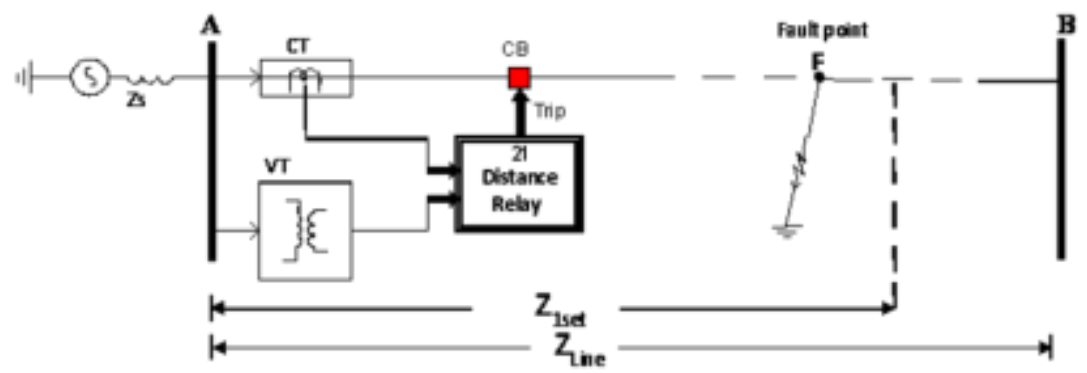

Figure 1. Distance Protection Scheme 
The apparent impedance $\left(Z_{a p}\right)$ and line impedance $\left(Z_{\text {Line(sec })}\right)$ on secondary side, are given by Eq. 1 and Eq. 2

$$
\begin{aligned}
& Z_{\text {ap }}=\frac{V T_{\text {Secondary }}}{C T_{\text {Secondary }}} \\
& Z_{\text {Line (Sec) })}=\frac{C T R}{V T R} \times Z_{\text {Line }}
\end{aligned}
$$

Where, CTR and VTR are CT and VT ratios respectively.

Zone-1 setting, $Z_{\text {Iset }}$ of DR used for protection of line $\mathrm{AB}$ is given by Eq.3

$$
Z_{1 \text { set }}=80 \% \text { of } Z_{\text {Line }(\mathrm{sec})}
$$

The DR compares $Z_{a p}$ with $Z_{\text {Iset }}$ to find the location of the fault, which may be inside or outside the protected zone. The DR issues trip signal instantaneously if $Z a p \leq Z_{\text {Iset }}$ and with specified time delay if $Z a p>Z_{1 s e t}$. Thus the signals received from VT and CT plays an important role for correct and reliable operation of distance protection scheme.

\section{B. Current Transformer}

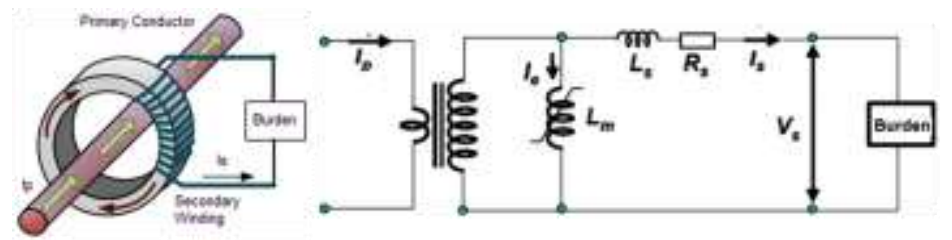

Figure 2. CT and its Equivalent circuit

The current transformer is used to replicate primary current $\left(I_{p}\right)$ on secondary side with certain transformation ratio $(n)$ based on the ratings of burden (meters or relays). When the fault occurs, the fault current $\left(i_{\text {fault }}\right)$ invariably has DC offset or in other words the AC component $\left(i_{A C}\right)$ is superimposed over DC component $\left(i_{D C}\right)$. The total fault current is given by Eq.4 [25].

$$
i_{\text {Fault }}(t)=i_{A C}(t)+i_{D C}(t)=I_{m} \operatorname{Sin}(\omega t+\alpha-\emptyset)+I_{m} \operatorname{Sin}(\alpha-\emptyset) e^{-\frac{t R}{L}}
$$

Where,

$I_{m}=$ Maximum value of $i_{A C}, \alpha=$ fault angle, $\varnothing=$ Transmission line characteristics angle;

$R=$ Transmission line resistance, $L=$ Transmission line inductance.

The DC in CT primary causes increase in total flux (flux due to $i_{A C}$ and $i_{D C}$ ), which is more than knee point flux of the CT core. This total flux causes CT to saturate. In this saturation process most of the transformed current, $\left(I_{p} / n\right)$ gets diverted through magnetizing branch (Figure. 2) and the current supplied to burden, $\left(I_{s}\right)$ gets clipped [26].

\section{Rogowski Coil}

Normally RC are torroidal coils with core made up of light weight non magnetic insulating material (NMIM). The light weight core makes them lighter in weight as compared to iron core $\mathrm{CT}$. The NMIM core in the coil structure makes the relative permeability ( $\mu \mathrm{r})$ of RC as unity. $\mathrm{RC}$ is always placed around the conductor whose current is to be measured. RC arrangement and equivalent circuit is shown in Figure 3 [23]. 


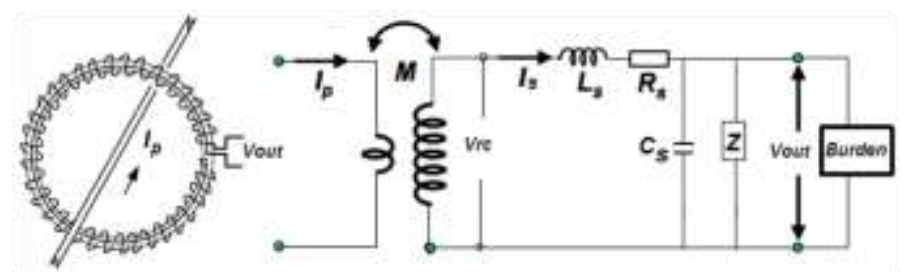

Figure 3. Rogowski coil and its equivalent circuit

The Voltage induced in the coil $\left(V_{r c(t)}\right)$ by current $i_{p}(t)$ is given by Eq.5.

$$
V_{r c(t)}=-M \frac{d i_{p}(t)}{d t}
$$

Where, $i_{p}$ is the current which is to be sensed and $M$ is the mutual coupling between primary conductor and secondary winding [27].

The RC output voltage $\left(\mathrm{V}_{\text {out }}\right)$ in Laplace domain is given by Eq.6.

$$
V_{\text {out }}=V_{r c}\left[\frac{Z}{S^{2} L_{S} Z C_{S}+S\left(L_{S}+R_{S} Z C_{S}\right)+\left(R_{S}+Z\right)}\right]
$$

\section{Difference between Rogowski Coil and Coreless CT}

Coreless CT can be called as air core CT. Rogowski coil (RC) basically uses a core made up of NMIM such as plastic/epoxy/silicone rubber to support the secondary winding. This NMIM also helps to provide galvanic isolation between primary and secondary. Silicone rubber core makes RC flexible. Flexible Rogowski Coils are convenient for measuring electric current in large or awkwardly shaped conductors, where space around the conductor is restricted or where only a lightweight transducer can be suspended on the conductor. This makes RC as ideal current transducer for retrofitting applications [28].

Coreless CT and Rogowski coil are non saturable instrument transformers which provide linear characteristics over wide operating current range for normal and abnormal power system conditions. But especially RC is designed in such a way to overcome the following issues which may arise while dealing with coreless CT [22-23].

1. The relative position of the primary conductor inside the coil loop should not affect the coil output signal.

2. The effect of electromagnetic field (cross-talk) produced by nearby conductors carrying high currents on coil output signal should be minimal.

To satisfy the first condition, Mutual inductance $\boldsymbol{M}$ of RC must have a steady value for any position of the primary conductor inside the coil loop. This can be achieved by

i. Providing a coil over a NMIM core with constant cross-section $S$ (Figure. 4).

ii. Building a coil with constant turn density $\boldsymbol{n}$ (Figure. 4).

iii.

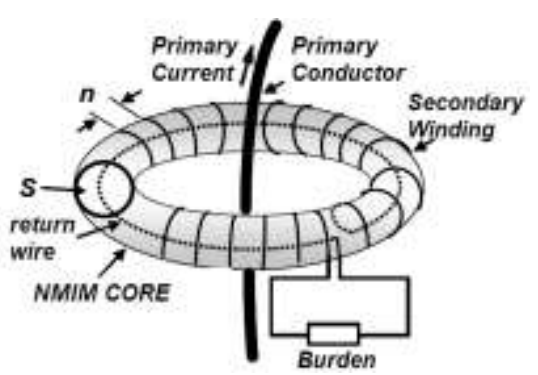

Figure 4. Rogowski coil and its construction

To satisfy the second condition, RC's are designed with two wire loops connected in electrically opposite directions. One or both loops can consist of wound wire. If only one loop 
is constructed as a winding, then the second wire loop can be constructed by returning the wire through or near this winding (Figure. 4). If both loops are constructed as windings, then they must be wound in opposite directions.

As the RC signal is a scaled time derivative of the primary current, signal processing is required to extract the power frequency signal for phasor-based distance relays. This may be achieved by integrating the RC output signals. The integrated signal accurately reproduces the primary current waveform.

A unique RC feature to measure the speed of current change can be used for special protection algorithms that would make decisions based on the change in the current slope instead on current magnitude.

\section{E. Disadvantages of $R C$}

1. To achieve high accuracy, Rogowski Coils should be connected to devices that have high input impedance.

2. Low sensitivity and requirement of shielding to avoid loss of signal

3. Temperature stability over wide operating current range

4. Integrator implementation

5. Low frequency noise magnification

6. Inability to drive multiple loads.

\section{Modeling and analysis of Distance Protection Scheme using PSCAD}

The stages involved while developing a distance protection scheme are shown in Figure.5.

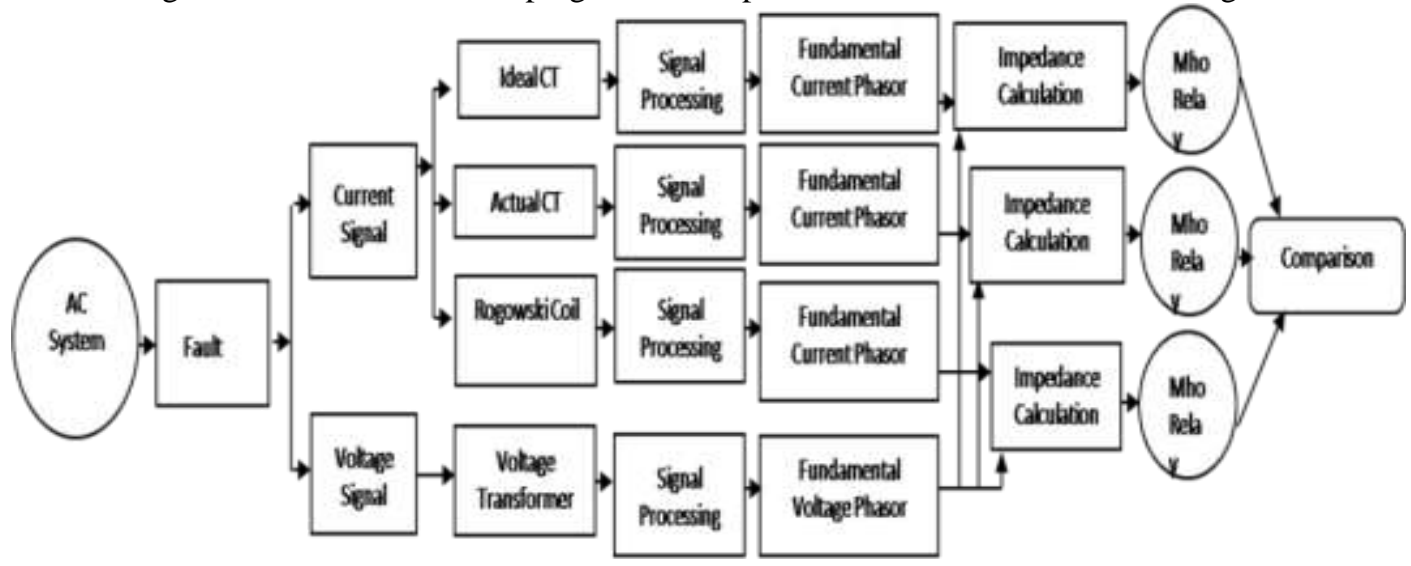

Figure 5. Distance protection scheme stages

The fault created on an AC system produces current and voltage signals with some transients. The voltage signal is collected with the help VT and the current signal is collected with the help of RC, ideal CT and actual CT simultaneously. In order to get correct value of the line impedance up to fault point, it is very essential to remove the transients and retain signals with fundamental frequency. So these signals are further processed through signal processing stage which carries FFT module. FFT module helps to obtain current and voltage signals at fundamental frequency. By using these current and voltage signals, $Z_{a p} s$ are calculated. Finally these $Z_{a p} s$ are fed to DR (Mho relays) which compares these impedances with its setting and issues trip signal instantaneously or with some time delay.

\section{A. Modelling of IEEE 9 Bus AC System}

The details of the IEEE 9 bus AC system model (Figure.6) are given in table 1[28]. Line between bus 7 and bus 8 (line 78) of IEEE 9 bus system is protected by using DR (Figure.6). The line 78 is divided in two parts as 78.1 and 78.2 to obtain its Zone 1 setting $\left(Z_{1 \text { set }}\right)$. The line 
lengths of these two parts can be varied to create a fault inside and outside of $Z_{\text {Iset }}$. Single line to ground (SLG) fault is created with the help of time fault logic [29].

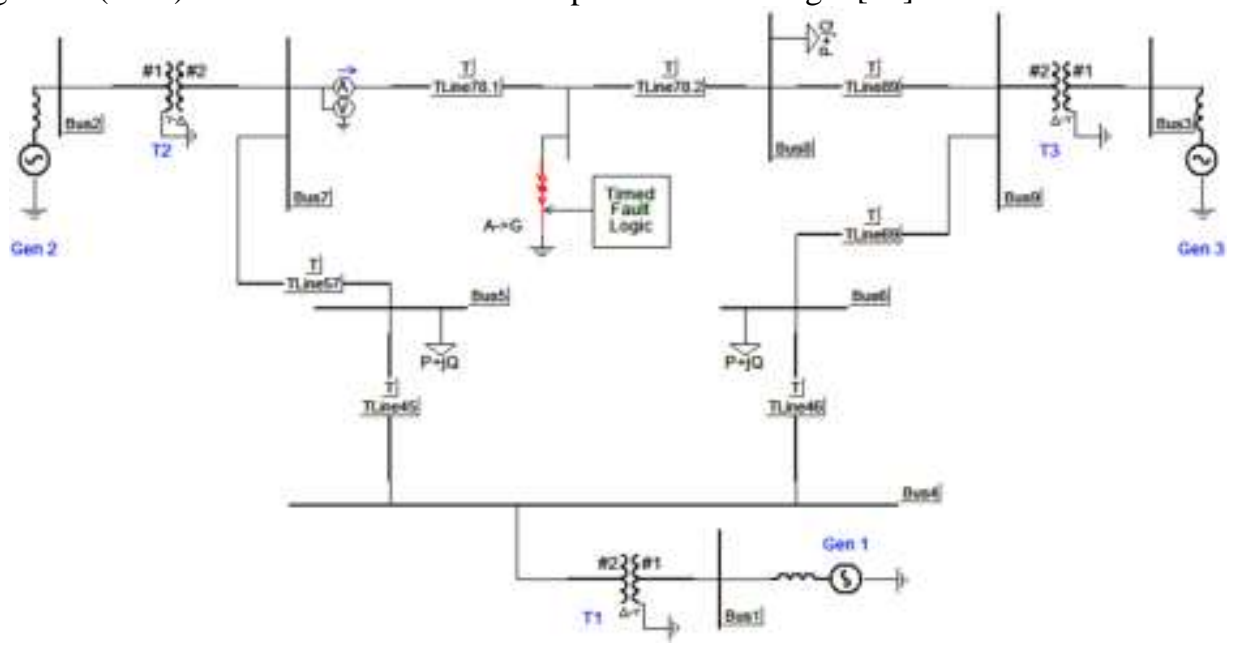

Figure 6. PSCAD model of IEEE 9 Bus AC system

Table 1. IEEE 9 Bus AC system details

\begin{tabular}{|l|l|}
\hline \multicolumn{1}{|c|}{ Parameter } & \multicolumn{1}{|c|}{ Specifications } \\
\hline Generator 1 & $16.5 \mathrm{kV}, 1.0098 \angle 0^{0} \mathrm{pu}$ \\
\hline Generator 2 & $18.0 \mathrm{kV}, 1.0065 \angle 5.1387^{0} \mathrm{pu}$ \\
\hline Generator 3 & $13.8 \mathrm{kV}, 1.0059 \angle 1.54780^{\circ} \mathrm{pu}$ \\
\hline 3 Phase Transformer T1 & $16.5 \mathrm{kV} / 220 \mathrm{kV}, 100 \mathrm{MVA}$ \\
\hline 3 Phase Transformer T2 & $18.0 \mathrm{kV} / 220 \mathrm{kV}, 100 \mathrm{MVA}$ \\
\hline 3 Phase Transformer T3 & $13.8 \mathrm{kV} / 220 \mathrm{kV}, 100 \mathrm{MVA}$ \\
\hline Length of Line 78,89,57,69,45 \& 46 & $100 \mathrm{~km}$ each \\
\hline +Ve seq. impedance of transmission line $($ per $\mathrm{km})$ & $0.2928 \angle 86.570 \Omega$ \\
\hline 0 seq. Impedance of transmission line $($ per $\mathrm{km})$ & $1.102 \angle 74.090 \Omega$ \\
\hline Load 1,2 \&3 & $(125+\mathrm{j} 50),(90+\mathrm{j} 30),(100+\mathrm{j} 35) \mathrm{MVA}$ \\
\hline
\end{tabular}

B. Modeling of Actual Current transformer

The actual CT with the following specifications is used (Figure. $7 \&$ table 2) [30].

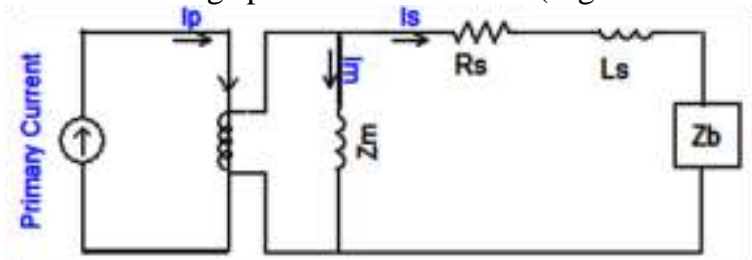

Figure 7. Actual CT Model

Table 2. CT Details

\begin{tabular}{|l|l|}
\hline \multicolumn{1}{|c|}{ Parameter } & \multicolumn{1}{c|}{ Specifications } \\
\hline CT ratio (CTR) & $270 / 1$ \\
\hline Secondary winding Resistance (Rs) & $0.5 \Omega$ \\
\hline Secondary winding Reactance (Xs) & $0.8 \mathrm{mH}$ \\
\hline Magnetic Core Area & $2.6 \times 10-3 \mathrm{~mm} 2$ \\
\hline Magnetic Path Length & $0.677 \mathrm{mtr}$ \\
\hline CT Burden (Zb) & $(0.5+\mathrm{j} 0.251) \Omega$ \\
\hline
\end{tabular}




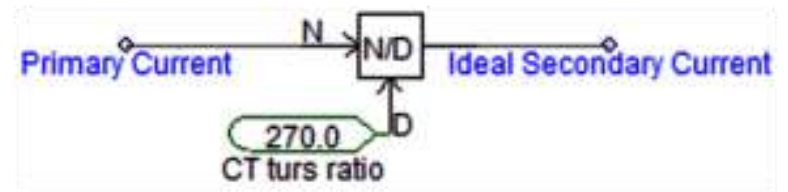

Figure 8. Ideal CT model

The primary current is divided by number of turns which have been considered in actual current transformer, to get ideal value of secondary current (Figure. 8).

D. Modelling of Rogowski Coil

The RC module \& integrator with the following specifications is used (Figure. $9 \&$ table 3 ) [31-32].

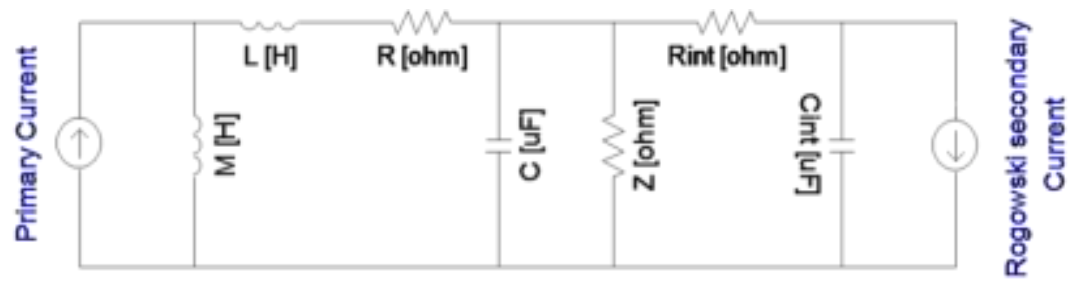

Figure 9. Rogowski Coil Model

Table 3. Rogowski Coil Details

\begin{tabular}{|l|l|l|l|}
\hline \multicolumn{1}{|c|}{ Parameter } & \multicolumn{1}{c|}{ Specifications } & \multicolumn{1}{c|}{ Parameter } & \multicolumn{1}{c|}{ Specifications } \\
\hline Mutual Inductance(M) & $437.9 \mu \mathrm{H}$ & R of Integrator(Rint) & $100 \Omega$ \\
\hline L of Rogowski Coil & $0.118 \mathrm{mH}$ & C of Integrator(Cint) & $1 \mu \mathrm{F}$ \\
\hline R of Rogowski Coil & $0.113 \Omega$ & No of turns & 270 \\
\hline C of Rogowski Coil & $217 \mathrm{pF}$ & Output RMS & $100 \mathrm{mV} / 1 \mathrm{kA}$ \\
\hline Z of Rogowski Coil & $5 \mathrm{k} \Omega$ & Rated Current & $100 \mathrm{kA}$ \\
\hline
\end{tabular}

\section{Case study and Simulation Results}

Using Eq. 2 and Eq. 3, $Z_{1 s e t}$ of line 78 is given by Eq. 7 .

$Z_{1 \text { set }}=0.135 \times 0.8 \times 100 \times 0.2928 \angle 86.57^{0}=3.1617 \angle 86.57^{0} \Omega$

To observe the under reach phenomenon of the DR, line length of 78.1 is adjusted as $70 \mathrm{~km}$ (Figure. 5).

After SLG fault, $Z_{a p}$ is given by Eq.8.

$$
Z_{\text {ap }}=0.70 \times 0.135 \times 100 \times 0.2928 \angle 86.57^{0}=2.76 \angle 86.57^{0} \Omega
$$

But due to external infeed from line 57 into bus 7, the actual impedance seen by the relay is given by Eq. 9 [33].

$$
\begin{aligned}
Z_{\text {ap actual }} & =\frac{\text { Current with no infeed }}{\text { Current with infeed }} \times Z_{\text {ap (Secondary })} \\
& =0.786 \times 2.96 \angle 86.57^{0}=2.17 \angle 86.57^{0} \Omega
\end{aligned}
$$




\section{A. Impact of CT secondary burden}

Burden connected to CT secondary is varied from $0.5 \Omega$ to $10 \Omega$, to observe the effect of $\mathrm{CT}$ saturation on secondary current, magnetization characteristics (B-H curve), $Z_{a p}$ trajectories and operating time of DR.

\section{A.1 Secondary currents waveforms:}

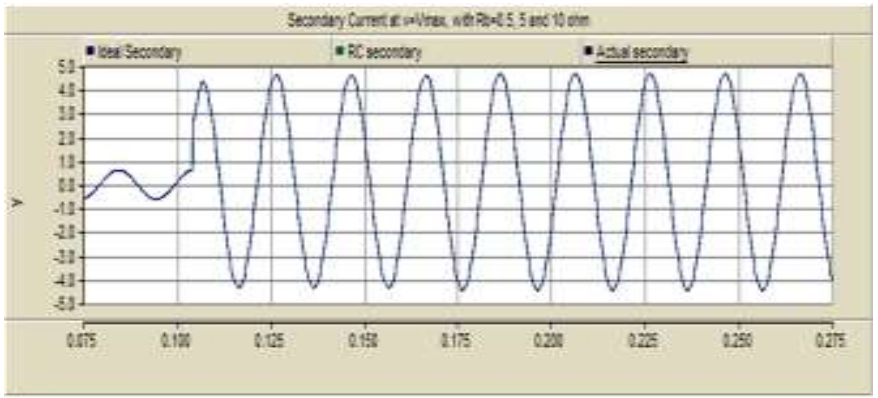

(a)

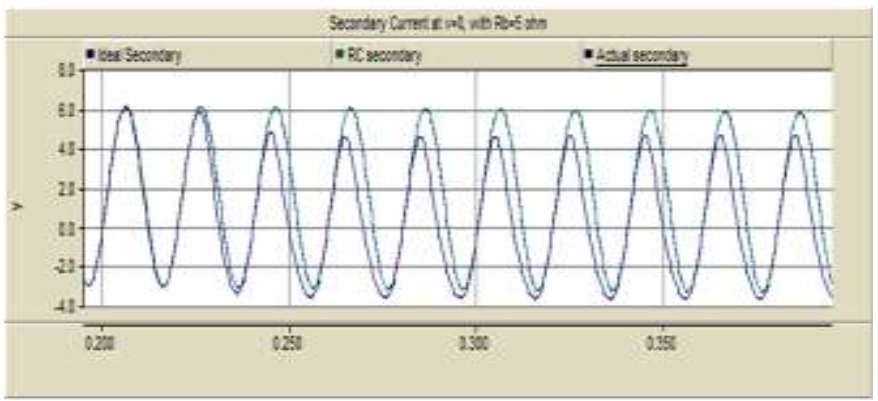

(b)

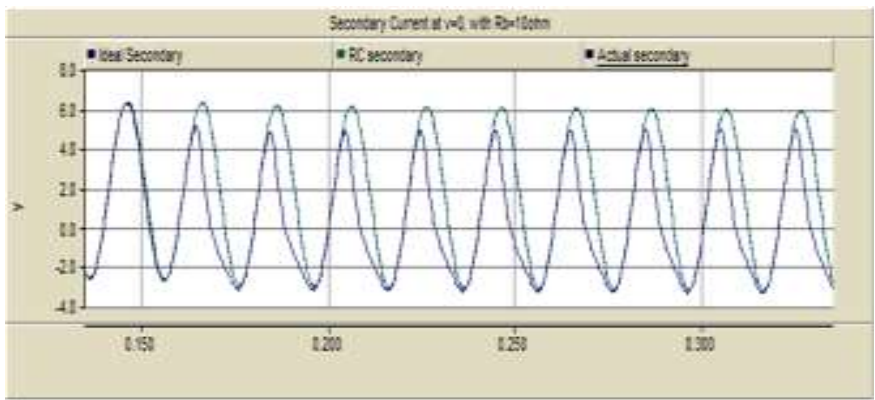

(c)

Figure 10. Secondary current waveforms at different burdens (a) $\mathrm{Rb}=0.5 \Omega \&$ fault at $\mathrm{v}=\mathrm{Vmax} \& \mathrm{v}=0 ;(\mathrm{b}) \mathrm{Rb}=5 \Omega \&$ fault at $\mathrm{v}=0$; (c) $\mathrm{Rb}=10 \Omega \&$ fault at $\mathrm{v}=0$

Figure 10a to 10c shows the secondary current waveforms generated by use of actual CT (blue) and RC (green). When the fault is created at maximum and zero value of voltage, with relay burden $(\mathrm{Rb})$ of $0.5 \Omega$, it is observed that actual CT and RC produces symmetrical secondary currents which are overlaying on each other (Figure. 10a). With the burden $(\mathrm{Rb})$ of 5 $\Omega$, when the fault is created at zero voltage, the current waveforms found to be shifted upwards from the reference due to DC offset and some distortions are observed in secondary current waveforms produced by actual CT (Figure. 10b). When Rb is increased to $10 \Omega$, the actual CT 
secondary waveform obtains more clipped and distorted shape (Figure. 10c). This proves that even relative small burden can influence CT accuracy if the fault current is not correctly anticipated.

To observe the performance of RC in DPS, different types of line to ground faults are created at different burden at different fault inception positions, ie. $\mathrm{v}=0$ and $\mathrm{v}=\mathrm{Vmax}$.

Table 4. Secondary currents at different CT burdens

\begin{tabular}{|l|c|c|c|c|}
\hline \multicolumn{1}{|c|}{ Fault Instant } & $\mathbf{v}=$ Vmax & \multicolumn{3}{c|}{ v= 0 } \\
\hline Relay Burden(Rb) & $0.5 \Omega$ & $0.5 \Omega$ & $5 \Omega$ & $10 \Omega$ \\
\hline Without CT (A) & 3.48 & 3.48 & 3.48 & 3.48 \\
\hline With CT (A) & 3.48 & 3.48 & 3.04 & 2.07 \\
\hline With Rogowski Coil (A) & 3.48 & 3.48 & 3.48 & 3.48 \\
\hline
\end{tabular}

Comparison of the secondary current root means square (rms) values at different burdens at different fault instant are given by table 4. It is observed that rms value of the secondary current produced by ideal CT and RC are approximately equal, but in case of actual CT it goes on reducing with increase in burden.

\section{A.2 B-H Curves of CT and Input-Output characteristics of RC}
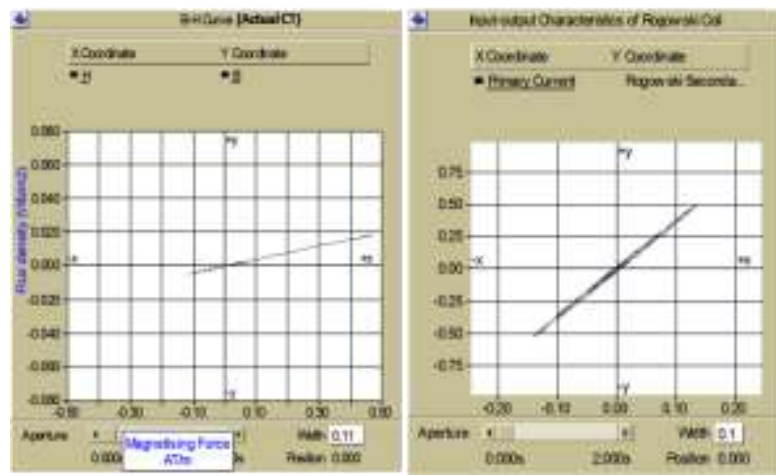

(a)
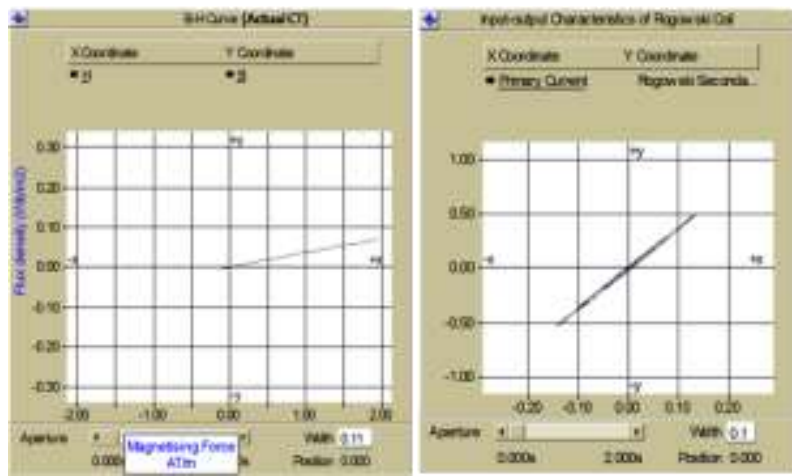

(b) 

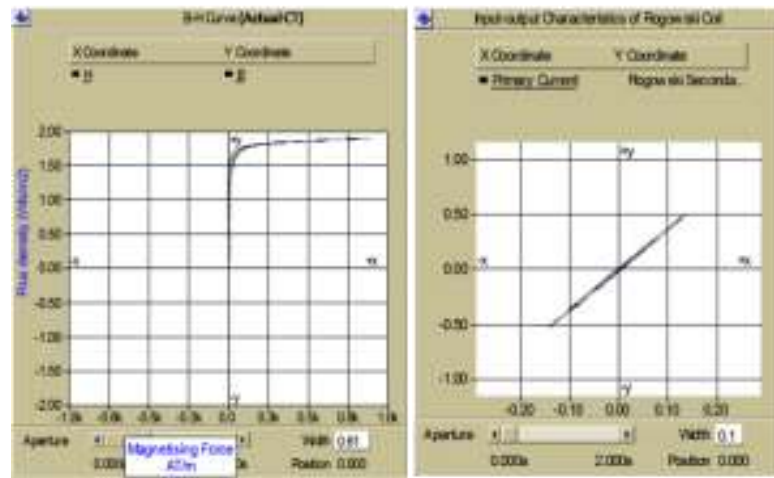

(c)

Figure 11. B-H Curves with

(a) $\mathrm{Rb}=0.5 \Omega \&$ fault at $\mathrm{v}=\mathrm{V} \max \& \mathrm{v}=0 ;$ (b) $\mathrm{Rb}=5 \Omega \&$ fault at $\mathrm{v}=0$;

(c) $\mathrm{Rb}=10 \Omega \&$ fault at $\mathrm{v}=0$

Figure 11a-11c shows, B-H curves generated by magnetization of actual CT and inputoutput characteristics of RC. RC maintains its linearity of secondary current with respect to primary current and found to be independent on fault instant and high value of connected burden (Figure. 11a-11c). Actual CT gives linear B-H curve (Figure. 11a), when the fault is created at $V \max \& \mathrm{v}=0$ with $\mathrm{CT}$ burden as $0.5 \Omega$. Saturated B-H curve of actual CT is observed, when the burden is increased to $5 \Omega$ (Figure. 11b). CT goes in deep saturation when the burden is increased to $10 \Omega$ (Figure. 11c).

After CT saturation, it is observed that, increase in CT burden increases magnetizing force required to produce same amount of flux density (Table 5).

Table 5. B \& H parameters at last saturation point with different burdens

\begin{tabular}{|l|c|c|c|c|}
\hline & \multicolumn{4}{|c|}{ Secondary Burden } \\
\hline Instant of Fault & $\mathrm{v}=\mathrm{V} \max$ & \multicolumn{3}{|c|}{$\mathrm{v}=0$} \\
\hline $\mathrm{Rb}($ Relay Burden) & $0.5 \Omega$ & $0.5 \Omega$ & $5 \Omega$ & $10 \Omega$ \\
\hline $\mathrm{B}(\mathrm{Wb} / \mathrm{m} 2)$ & 0.019 & 0.069 & 1.92 & 1.92 \\
\hline $\mathrm{H}(\mathrm{AT} / \mathrm{m})$ & 0.475 & 1.90 & 1464 & 2035 \\
\hline
\end{tabular}

\section{A.3 V-I Characteristics of Rogowski coil (Case Study)}

Rogowski coil which was installed in Gujarat state for Induction heating purpose is shown in Figure. 12 [34-35].

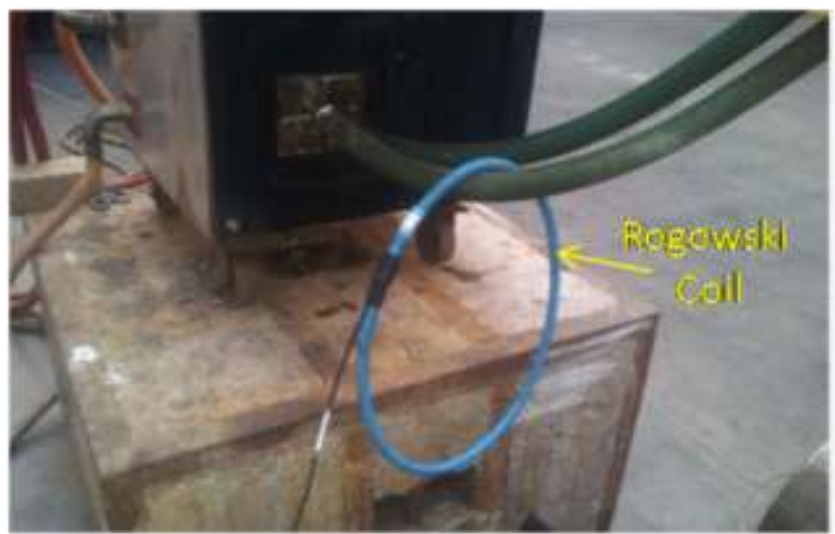

Figure 12. Installation of Rogowski coil for Induction heating application 
The results of the prototype installation for induction heating application are given in table 6. The input output characteristics of Rogowski coil is shown in Figure. 13. It is observed that the characteristics remain linear throughout the operating range of $0 \mathrm{Amp}$ to $10 \mathrm{kA}$.

Parameters observed on input and output side of Rogowski Coil

\begin{tabular}{cccc}
\hline Sr. No. & Input Current & Rogowski output voltage & Output from Integrator \\
\hline 1 & $10 \mathrm{KA}$ & $10 \mathrm{~V}$ & $20 \mathrm{~mA}$ \\
2 & $7.5 \mathrm{KA}$ & $7.5 \mathrm{~V}$ & $16 \mathrm{~mA}$ \\
3 & $5 \mathrm{KA}$ & $5 \mathrm{~V}$ & $12 \mathrm{~mA}$ \\
4 & $2.5 \mathrm{KA}$ & $2.5 \mathrm{~V}$ & $8 \mathrm{~mA}$ \\
5 & $0 \mathrm{~A}$ & $0 \mathrm{~V}$ & $4 \mathrm{~mA}$ \\
\hline
\end{tabular}

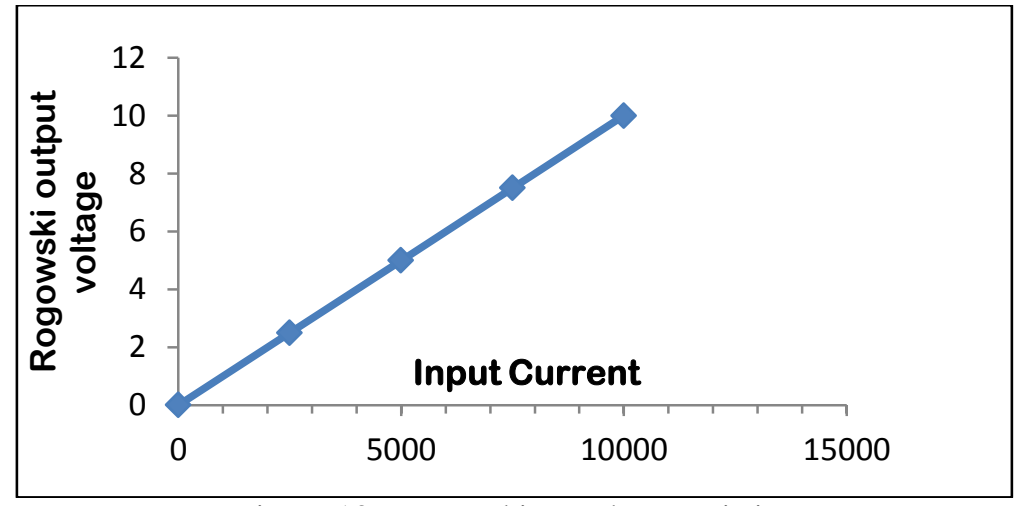

Figure 13. Rogowski V-I characetristics

\section{A.4 Apparent Impedance}

Figure. 14a to Figure. 14c shows Zap trajectories with ideal CT (blue), actual CT (green) and RC (red) along with Mho circle, when SLG fault is created at $70 \mathrm{~km}$.

Before saturation of CT, it is observed that all the Zap trajectories are overlaying on each other (Figure. 14a). Figure. 14b-14c shows that the Zap trajectory (green) is significantly impacted by the CT saturation. To have a correct tripping of the relay, Zap trajectory must fall inside Zone 1. But when the CT gets saturated, Zap trajectory lies outside of its Zone 1 boundary. As the CT comes out from saturation state, the impedance seen by DR (Mho element) matches the unsaturated plot. Therefore, DR shows to have a tendency to under reach.

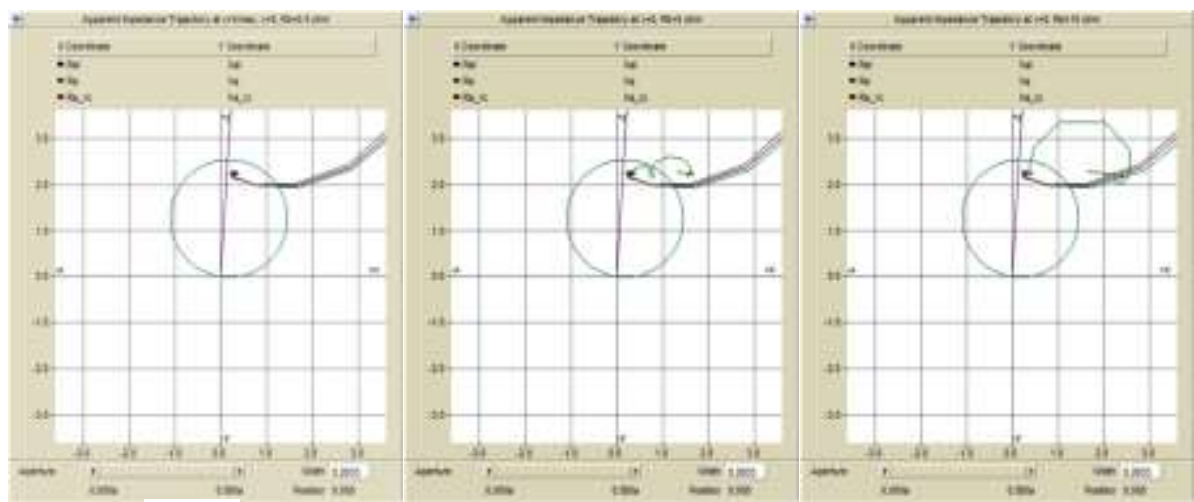

(a)

(b)

(c)

Figure 14. Impedance Trajectories with

a) $\mathrm{Rb}=0.5 \Omega \&$ fault at $\mathrm{v}=\mathrm{Vmax} \& \mathrm{v}=0 ;(\mathrm{b}) \mathrm{Rb}=.5 \Omega \&$ fault at $\mathrm{v}=0$;

(c) $\mathrm{Rb}=10 \Omega \&$ fault at $\mathrm{v}=0$ 
Table 7 gives the values of Zap obtained at different faults with different fault instants and increased burdens. The clipping of secondary current due CT saturation increases the magnitude of impedance seen by DR. It is observed that with increase in burden, the impedance seen by relay increases.

Table 7. Apparent Impedance values at different burden

\begin{tabular}{|l|c|c|c|c|c|c|c|c|}
\hline Instant of Fault & \multicolumn{2}{|c|}{$\mathbf{v}=$ Vmax } & \multicolumn{2}{c|}{$\mathbf{v}=\mathbf{0}$} & \multicolumn{2}{c|}{$\mathbf{5 \Omega} \mathbf{\Omega}$} \\
\hline $\begin{array}{l}\text { Relay } \\
\text { Burden(Rb) }\end{array}$ & \multicolumn{2}{|c|}{$\mathbf{0 . 5} \mathbf{\Omega}$} & \multicolumn{2}{c|}{$\mathbf{0 . 5} \mathbf{\Omega}$} & \multicolumn{2}{c|}{$\mathbf{5}$} \\
\hline & Magnitude & Phase & Magnitude & Phase & Magnitude & Phase & Magnitude & Phase \\
\hline Without CT (A) & 2.17 & 81.77 & 2.17 & 81.77 & 2.17 & 81.91 & 2.17 & 81.91 \\
\hline With CT (A) & 2.17 & 82.88 & 2.17 & 82.88 & 2.28 & 80.00 & 3.04 & 49.0 \\
\hline $\begin{array}{l}\text { With Rogowski } \\
\text { Coil (A) }\end{array}$ & 2.17 & 80.85 & 2.17 & 80.85 & 2.17 & 83.03 & 2.17 & 83.03 \\
\hline
\end{tabular}

A.5 Operating time:

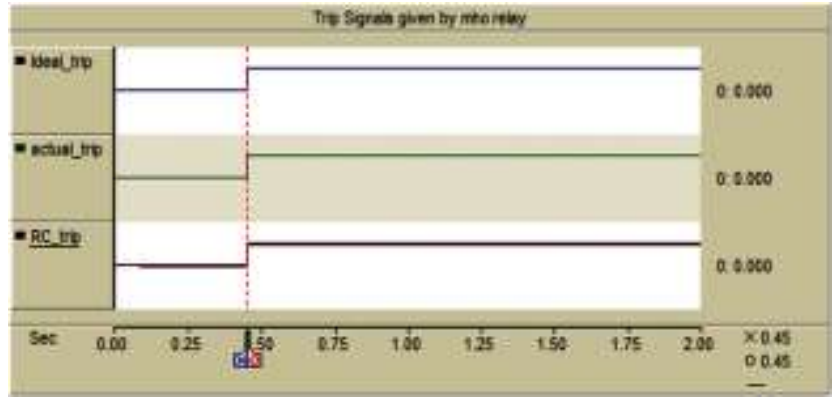

(a)

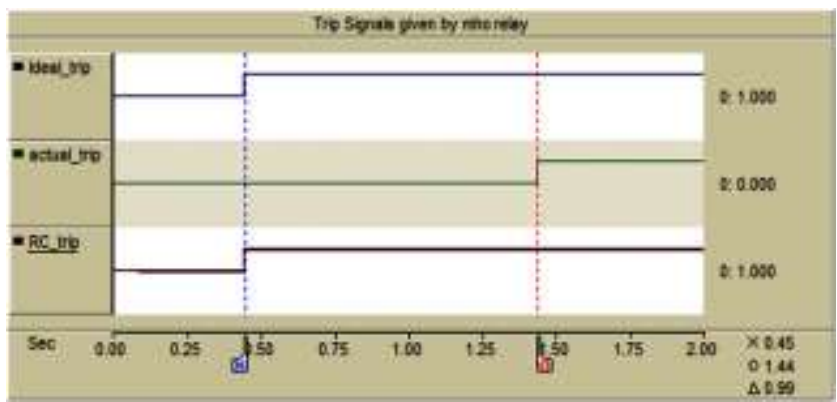

(b)

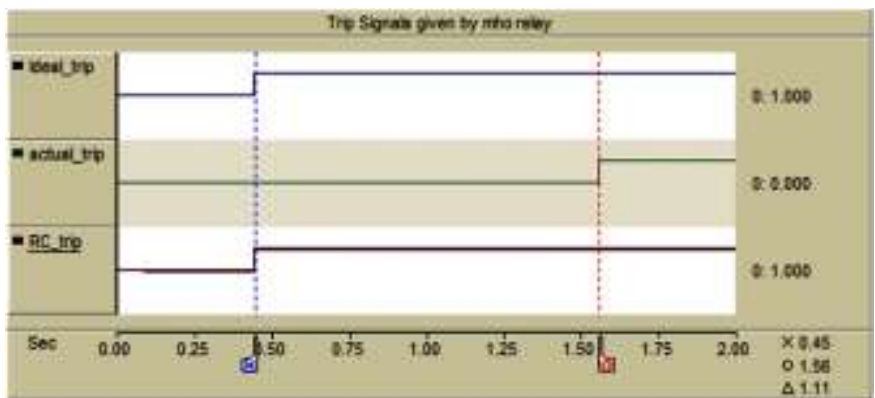

(c)

Figure 15. Tripping Signals with

(a) $\mathrm{Rb}=0.5 \Omega$ \& fault at $\mathrm{v}=\mathrm{Vmax} \&$ fault at $\mathrm{v}=0$; (b) $\mathrm{Rb}=5 \Omega$ \& fault at $\mathrm{v}=0$; (c)

$\mathrm{Rb}=10 \Omega \&$ fault at $\mathrm{v}=0$ 
The operating time of a DR (Mho relay) is considerable to make sure of high speed tripping. Before CT saturation, all Mho relay elements issues their tripping signals at same instant (Figure. 15a-15b). When CT burden is increased from $2.5 \Omega$ to $10 \Omega$, CT goes in deep saturation. This CT saturation process causes the $Z_{a p}$ to lie outside Zone1 for some time and to return back inside zone1 when CT comes out of saturation. It delays Mho relay element operation connected to actual CT and result in slower than expected tripping times (Figure. $15 \mathrm{c}-15 \mathrm{e})$.

Table 8. Tripping Times at Different Burdens

\begin{tabular}{|l|c|c|c|}
\hline & \multicolumn{3}{|c|}{ Tripping Time } \\
\hline Fault Instant & $\mathrm{v}=\mathrm{Vmax}, \mathrm{v}=0$ & \multicolumn{2}{|c|}{$\mathrm{v}=0$} \\
\hline Relay Burden & $0.5 \Omega$ & $5 \Omega$ & $10 \Omega$ \\
\hline Without CT & Instantaneous & Instantaneous & Instantaneous \\
\hline With CT & Instantaneous & After 0.99 S & After 1.11 S \\
\hline With RC & Instantaneous & Instantaneous & Instantaneous \\
\hline
\end{tabular}

Table 8 gives the time required for MDR to operate, when the burden is increased from 0.5 $10 \Omega$. It is observed that increase in CT burden, increases the magnitude of the Zap, causing delay in the time of operation.

\section{Conclusion}

Low voltage case study and PSCAD simulations shows superiority of RC as current transducer over conventional iron core CT. Increased CT secondary burden (0.5-10 $\Omega$ ) and presence of dc offset in fault current causes a CT to produce a highly distorted and clipped secondary current. Distortion reduces effective value of secondary current. The problem becomes more critical when fault takes place near to the boundary of first zone of Distance Relay (DR). In this situation the DR observes this fault in its second zone for initial 10 cycles of current waveform. This fault re-enters in first zone when secondary current regains its original shape. Ideally this fault needs to be attempted instantaneously. This can cause the DR to under reach and trip after a longer period of time than it was originally anticipated. Rogowski coil produces exact replication of primary current without distorting it with any load burden and prevent DR from under reach phenomenon.

\section{References}

[1]. Stanley H. Horowitz, Arun G. Phadke, "Power System Relaying", John Wiley \& Sons Ltd, ISBN: 978-0-470-05712-4, Third Edition, 2008.

[2]. "Protection Application Handbook", ABB, BA THS / BU Transmission Systems and Substations

[3]. “Instrument Transformer Application Guide”, ABB, High Voltage Products

[4]. Walter A. Elmore, "Pilot Protective Relaying", ABB Automation and Marcer Dekker Inc., ISBN:0-8247-8195-3, Year:2000.

[5]. IEEE Power Engineering Society, "IEEE Standard Requirements for Instrument Transformers-IEEE Std C57.13 ${ }^{\mathrm{TM}}-2008^{\prime \prime}$, The Institute of Electrical and Electronics Engineers, Inc., July 2008.

[6]. Piotr Sawko, "Impact of Secondary Burden and X/R Ratio on CT Saturation" Wroclaw University of Technology, Faculty of Electrical Engineering, 2008:1-3. [zet10.ipee.pwr.wroc.pl]

[7]. Pentti Mahonen, Vesa Virtanen, Tapio Hakola, "The Rogowski coil and the voltage divider in power system protection and monitoring", $A B B$ Transmit and substation $O y$, Vaasa, Finland

[8]. A.Wiszniewski; J.Szafran, "Distance digital algorithm immune to saturation of current tra nsformers", Fourth International Conference on Developments in Power Protection, 1989:196 - 199. 
[9]. Y. C. Kang J. K. Park ; S. H. Kang ; A. T. Johns ; R. K. Aggarwal, "An algorithm for compensating secondary currents of current transformers", IEEE Transaction on Power Delivery, 1997;12:116-124, DOI: 10.1109/61.568231

[10]. S.. Bittanti, F. A. Cuzzola, F. Lorito, and G. Poncia, "Compensation of nonlinearities in a current transformer for the reconstruction of the primary current," IEEE Trans. Control Sys. Technol., vol. 9, no. 4, pp. 565-573, Jul. 2001. DOI:10.1109/87.930967

[11]. J. Pan, K. Vu, and Y. Hu, "An efficient compensation algorithm for current transformer saturation effects," IEEE Trans. Power Del., vol. 19, no. 4, pp. 1623-1628, Oct. 2004. DOI: $10.1109 /$ TPWRD.2004.835273

[12]. Hyun-Woong Lee; Yong-Cheol Kang; Sung-Il Jang; Yong-Gyun Kim, "Distance relay suitable for use with a measurement type current transformer" IEEE Conference on Power Tech, 2007: 1176 -1181, DOI: 10.1109/PCT.2007.4538482

[13]. Ferry A. Viawan; Jianping Wang; Zhao Wang; Winnary-Ying Yang, “ Effect of current sensor technology on distance protection", IEEE/PES Power Systems Conference and Exposition, 15th -18th March 2009:1-7, DOI: 10.1109/PSCE.2009.4840177

[14]. B. Ajaei, M. Sanaye-Pasand, M. Davarpanah, A. Rezaei-Zare, and R. Iravani, "Compensation of the current-transformer saturation effects for digital relays," IEEE Trans. Power Del., vol. 26, no. 4, pp. 2531-2540, Oct. 2011. DOI:10.1109/TPWRD.2011.2161622

[15]. Soumya R. Mohanty, V. Ravikumar Pandi, B.K. Panigrahi, Nand Kishor, Prakash K. Ray, "Performance Evaluation of Distance Relay with CT saturation", Elsevier Journal of Applied Soft Computing, December 2011;11(8): 4789-4797, DOI:10.1016/j.asoc.2011.07.003

[16]. Sinisa J. Zubic, Milenko B. Djuric, "A distance relay algorithm based on the phase comparison principle:, Electric Power Systems Research, November 2012;98:20-28, DOI: 10.1016/j.epsr.2012.05.017

[17]. A. Hooshyar and M. Sanaye-Pasand, "Accurate measurement of fault currents contaminated with decaying dc offset and ct saturation," IEEETrans. Power Del., vol. 27, no. 2, pp. 773-783, Apr. 2012. DOI: 10.1109/TPWRD.2011.2176965

[18]. M. Moghimi Haji, B. Vahidi, S.H. Hosseinian, "Current Transformer Saturation Detection Using Gaussian Mixture Models", Journal of Applied Research and Technology, February 2013;11(1):79-87, DOI: 10.1016/S1665-6423(13)71516-5

[19]. Hector J.Altuve, Normann Fischer, Gabriel Benmouyal, Dale Finney, "Sizing current transformers for line protection applications", 66th Annual Conference on Protective Relay Engineers, 2013: 36 - 51, DOI: 10.1109/CPRE.2013.6822025.

[20]. Mohsen Tajdinian, Mehdi Zareian Jahromi, Kazem Mohseni, Shahram Montaser Kouhsari, "An analytical approach for removal of decaying DC component considering frequency deviation", Electric Power Systems Research, January 2016;130:208-219, DOI:10.1016/j.epsr.2015.09.007.

[21]. F.A. Pereira, F.C.F. Guerra, B.A. Sousa, E.N.A. Santos, N.S.D. Brito, U.A. Carmo, "Real time compensation algorithm for air-gapped current transformers saturation effects", Electric Power Systems Research, online availability on 7th April 2016, DOI:10.1016/j.epsr.2016.03.035

[22]. IEEE PSRC report, "Practical Aspects of Rogowski Coil Applications to Relaying", Power System Relaying Committee of the IEEE Power Engineering Society, September 2010:1-72, http://www.pessrc.org/Reports/Practical\%20Aspects\%20of\%20Rogowski\%20Coil\%20Applications\%20t o\%20Relaying_Final.pdf

[23]. Veselin Skendzic and Bob Hughes, Schweitzer Engineering Laboratories, Inc. "Using Rogowski Coils Inside Protective Relays", 66th Annual Conference for Protective Relay Engineers College Station, Texas, 8th -11th April 2013, DOI:10.1109/CPRE.2013.6822022 
[24]. Avinash N. Sarwade, Pradeep K. Katti andJayant G. Ghodekar, "Optimum Setting of Distance Protection Scheme for HV Transmission Line", Journal of Power Electronics and Power Systems, STM, 2013;3(2):23-30.

[25]. Paithankar Y.G., S.R. Bhide, "Fundamentals of Power System Protection", PHI Learning Pvt Ltd, ISBN: 8120341236, 97881203412342010, 2010

[26]. Lecture Notes- NPTEL, "Electrical Engineering-Power Sytem Protection", 2009, Chapter 7

[27]. Sudha, K.R. Valluvan, T. Basavraju, "Fault Diagnosis of Transmission Lines with Rogowski Coils as Current Sensors", International Journal of Computer Applications, May 2013;70(25):19-25, [research.ijcaonline.org

[28]. Power System simulation software, "PSCAD/EMTDC 4.2.1", Manitoba HVDC Research Centre Inc., Canada, 2008

[29]. Hongyan Teng, Chongru Liu ; Minxiao Han ; Shiying Ma ; Xiaojiang Guo, "IEEE9 Buses System Simulation and Modeling using PSCAD" Asia-Pacific Power and Energy Engineering Conference, 28th-31st March 2010: 1-4, DOI: 10.1109/APPEEC.2010.5448242

[30]. Dharshana Muthumuni, Lisa Ruchkall, and Dr. Rohitha Jayasinghe, "Modelling Current Transformer saturation for detailed Protection studies", Pulse Newletter, Manitoba HVDC Research Centre, Dec. 2011:1-4, https://hvdc.ca/uploads/ck/files/newsletters/Pulse_Dec2011.pdf

[31]. Fulufhelo Andrew Netshiongolwe and John Michael van Coller, "Electrical Stress Monitoring of Distribution Transformers using Bushing Embedded Capacitive Voltage Dividers and Rogowski Coils ", Proceeding of International conference on Power System Transients-56, 15th -18th June 2015:1-8, http://www.ipstconf.org/papers/Proc IPST2015/15IPST056.pdf

[32]. Murtaza Hashmi and Matti Lehtonen, "Effect of Rogowski coil and covered conductor parameters on the performance of PD measurements in Overhead distribution Networks", 16th PSCC, Glasgow, Scotland, 14th -18th July 2008:1-7

[33]. Juan M. Gers, Edward J. Holmes, Chapter 9, "Distance Protection", Protection of Electricity Distribution Networks, The Institution of Engineering and Technlogy Power and Energy Series-47, 2nd Edition, 2004:173-223.

[34]. Ashish S. Paramane, Avinash N. Sarwade, Pradeep K. Katti and Jayant G. Ghodekar, "Rogowski Coil - A Novel Transducer for Current Measurement", 6th International Conference on Power System Protection and Automation, CBIP, New Delhi, India, 27th 28th February 2014:80-88.

[35]. Datasheet, "MFC-150-Flexible Rogowski Coil”, 1DAUMFC15004, Algodue Electronica, Italy. 


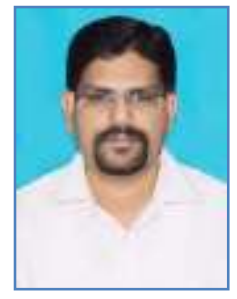

Avinash Namdeo Sarwade received his bachelor degree in Electrical Engineering from Walchand College of Engineering, Sangali, Shivaji University, Kolhapur, in 1998 and M. Tech (Power System) from College of Engineering Pune, University of Pune in 2006. Presently he is pursuing Ph. D from Dr. Babasaheb Ambedkar Technological University, Lonere and working as faculty member in Sinhgad College of Engineering, Pune. His area of research is Power System Protection.

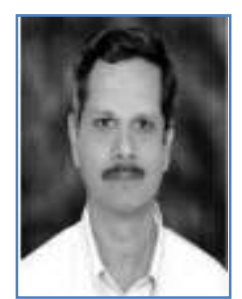

Pradeep K. Katti received his Bachelor degree in Electrical Engineering from Bapuji Institute of Engineering and Technology, Davanagere, Mysore University's in 1985, M.E. (Control System) from College of Engineering Pune, University of Pune in 1991 and Ph. D in Energy system from Visvesvaraya National Institute of Technology, Nagpur in 2007. He has a wide teaching experience and presently working as Professor in Department of Electrical Engineering, Dr. Babasaheb Ambedkar Technological University, Lonere, India. He has a large no. of publications in National and International Journals on his credit. His area of research is Renewable Energy.

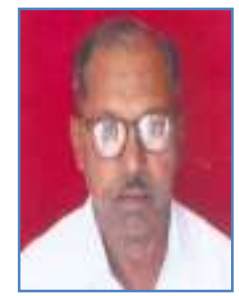

Jayant G. K. Ghodekar received his Bachelor and Masters degree in Electrical Engineering from College of Engineering Pune, University of Pune in 1964 \& 1975 respectively and Ph. D in Control system from IIT Delhi in 1985. He has a large no. of publications in National and International Journals on his credit. His area of research is Control System. 